\title{
An Ongoing Omission: Adolescent and Adult Malnutrition in Famine Situations
}

\section{Peter Salama \& Steve Collins}

\begin{abstract}
Prolonged famine causes malnutrition in all age groups. The under five age group is systematically targeted for nutritional interventions in the majority of complex emergencies where famine is a major component. Older children and adults however, are often not targeted systematically or are excluded completely. This is despite the past experience in Somalia, Angola and more recently southern Sudan, of sustained high adolescent and adult mortality rates associated with malnutrition. Using the recent example of southern Sudan, the authors analyze some of the reasons for this omission, which include factors such as inadequate scientific literature, the bias of conventional nutritional epidemiology, agency inexperience and media and funding pressures. Finally the authors call for a greater amount of attention and resources to be targeted towards these age groups by the humanitarian community. Programmes should be accompanied by operational research within the framework of a common research agenda.
\end{abstract}

\section{Résumé}

La famine prolongée engendre la malnutrition dans tous les groupes d'âge. Le groupe des moins de cing ans est systématiquement ciblé pour intervention nutritionnelle dans la majorité des situations d'urgences complexe où la

Peter Salama was at the time of writing the medical co-ordinator for emergencies for the Irish $N G O$ Concernand was the emergency co-ordinator for southern Sudan between August to December 1998.

Steve Collins is an independent consultant in nutrition and health who was involved in the design of the Concern programme for adolescents and adults in Ajiep. famine est un composant majeur. Les autres enfants et les adultes, pour leur part, sont souvent ciblés très sporadiquement, ou même complètement exclus. Cette situation seperpétuemalgré les expériences passées en Somalie, en Angola, et, plus récemment, au SudSoudan, où un taux constant de mortalité adolescente et adulte ontété associés à la malnutrition. Ensebasant surl'exemple récent du Sud-Soudan, les auteurs analysent certaines des raisons de ces omissions, cequi inclut des facteurs tels: une documentation scientifique inadéquate, les préjugés de l'épidémiologie nutritionnelle tra-ditionnelle, l'inexpérience des agences et des médias, et les pressions issues des sources de financement. Les auteurs font un appel pour qu'une plus grande attention et de plus amples ressources soient consacrées, par la communauté humanitaire, à cibler les adolescents et les adultes dans les situations de famine. De plus, les programmes d'aide devraient s'accompagner d'investigations opérationnelles effectuées dans le cadre d'objectifs de recherche communs.

\section{Introduction}

The year of the 1998 famine will go down as another disastrous period in the history of southern Sudan. Once again aid agencies rushed in to deliver services as Operation Lifeline Sudan (OLS) and non-OLS agencies alike, either initiated or expanded operations in response to the humanitarian crisis. The international donors poured millions into OLS, which expanded into one of the largest emergency operations in history. As the rains end and the cease-fire, that has allowed the response in Bahr el Ghazal to continue, draws to a close, it will be important to evaluate the quality of the humanitarian intervention in southern Sudan. In particular, the prioritisation of resources is a key area that should be closely examined. This article focuses on one aspect of humanitarian intervention; the choice of target groups for selective feeding interventions.

\section{The Focus on Child Malnutrition}

By August 1998, according to the United Nations Children Fund's (UNICEF) figures, there were 18 Non-Governmental Organisations (NGOs) operating 50 Supplemental Feeding Centres (SFCs) and 21 Therapeutic Feeding Centres (TFCs) in Bahrel Ghazal (see map) with anticipated numbers of beneficiaries of 40,753 and 6,430 respectively. ${ }^{1}$ To our knowledge, not one of these centres provided services tailored towards older children and adults. Although some centres did include small numbers of adults, particularly if they were categorised as 'vulnerable' (disabled, elderly, pregnant and lactating women), the inclusion of adolescents and adults was generally on an ad hoc basis. This focus on child malnutrition did not always correspond with the mortality patterns in a given location. In a number of areas, typical of a late stage in a severe famine, adult and adolescent deaths out-numbered those of children under the age of five. ${ }^{2}$ The inappropriately low amount of resources targeted towards acutely malnourished adults and adolescents indicates a failure to rationally prioritise relief interventions in order to address the vital needs of this population.

\section{Past Lessons Forgotten}

Lessons, supposedly learnt in Somalia and Angola, about the importance of treating malnutrition in all sections of the population appeared to have been forgotten. The inattention to the plight 
of malnourished adults and adolescents, characteristic of most humanitarian responses to famine and war since the Second World War, returned. During 1992 in Baidoa, Somalia, although adults and adolescents accounted for two thirds of recorded deaths, there were almost no specialised nutritional services for these age groups, who were instead, expected to recover on a basic ration of rice and beans. ${ }^{3}$ The success of the single adult therapeutic centre in the town prompted a rethink as to the importance of adult and adolescent malnutrition in famine. By the following year some lessons had been learnt. In the town of Melange, Angola, where the mortality picture was again similar, with $75 \%$ of the bodies buried during the first few months of the aid operation aged more than 10 years,4,s adult therapeutic services figured strongly in the response. This increased attention towards adult feeding continued, and in more recent relief operations, for examp Ie in the Great Lakes region since 1994, or in Liberia during 1996/7, specialised adult feeding centres have played important roles in the humanitarian response.

\section{Why Were Malnourished Adults and Adolescents Neglected?}

In view of these recent experiences and successes with feeding programmes targeted towards adults, why was this target group neglected in southern Sudan? The reasons are complex. Many factors, such as the inadequacy of the literature on the problems of starving adults, the focus of nutritional epidemiology on the under five age group, inex , perience, the short history of contemporary adult selective feeding programmes, media expectations and funding pressures, are all important. These are explored in the following paragraphs.

\section{Diagnosis and Treatment of} Malnourished Adolescents and Adults still in its 'Infancy' There is little good scientific literature available on the diagnosis and treat-

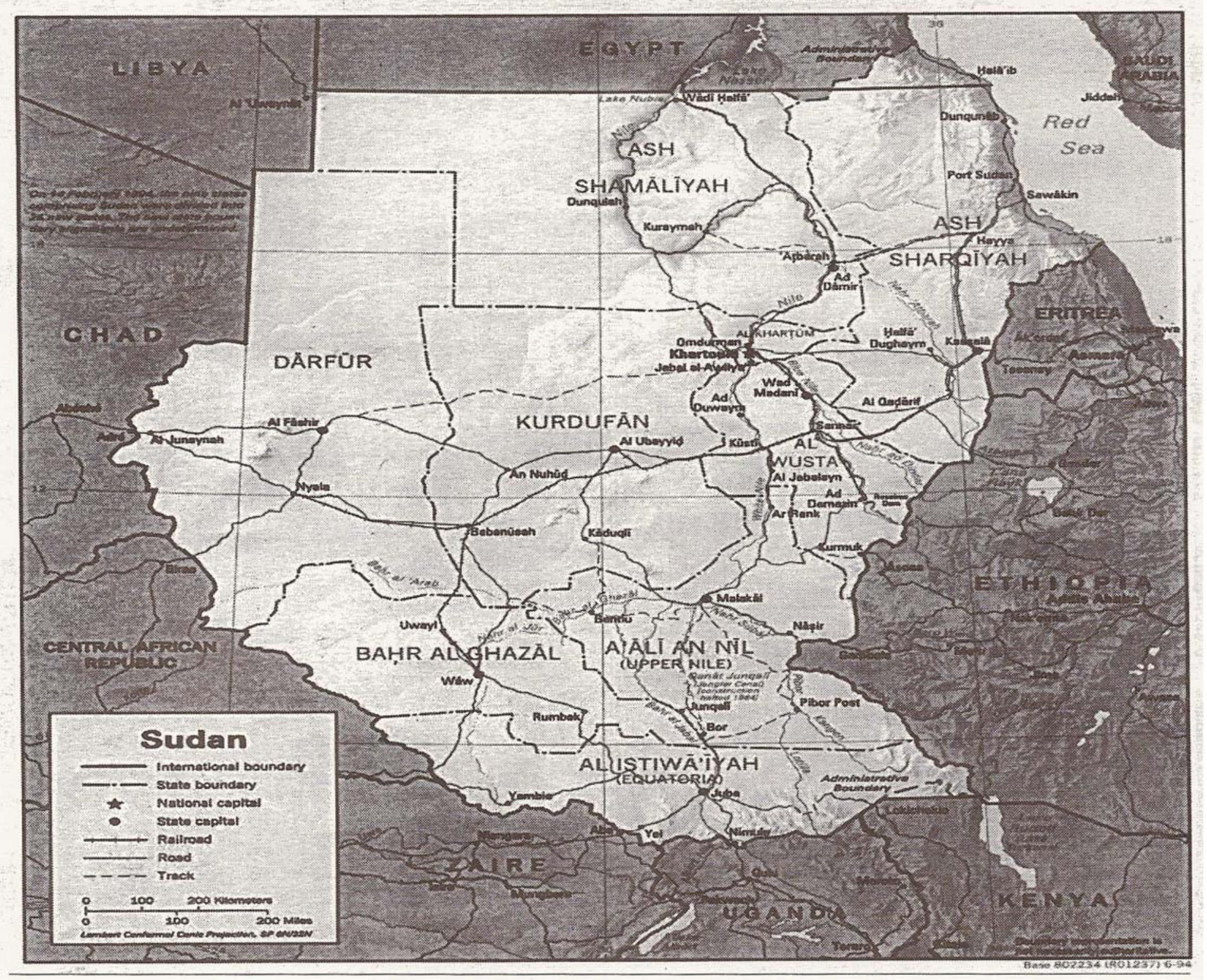


ment of malnourished adolescents and adults, and the tools for assessing these age groups in the field remain primitive. As recently as 1996, Mason et al. were unable to find any studies on the relative risk of mortality from under-nutrition in adults. ${ }^{6}$ There is still little uniformity in the international standards and accepted protocols for adult nutrition programmes. Body mass in$\operatorname{dex}(\mathrm{BMI})$, in vogue for the assessment of chronic malnutrition in adults is problematic. Large individual variations in body shape, particularly the relative lengths of the legs and back can alter individual BMIs by as much as $4 \mathrm{~kg} / \mathrm{m}^{2}$ irrespective of nutritional status. Whilst these differences can be corrected on a population level, by adjusting BMI values using the "Cormic Index" (sitting height/standing height), such adjustments are not practical on an individual basis for screening admissions to feeding centres. The height and weight measurements required can also be difficult to obtain in severely malnourished adults. Although admission indicators based upon a combination of MUAC and clinical criteria are being developed, measurement error can be significant and the problem of appropriate discharge criteria remains. For adolescents, especially post-pubertal adolescents (and particularly in the 'nilotic' people of southern Sudan) the level of knowledge is even more basic. Extended weight for height charts are poor predictors of mortality and extended BMI for height charts have as yet been used infrequently, remain invalidated and are likely to suffer from similarproblems as BMI in adults. The use of MUAC for adolescents, although promising, has not yet been adequately explored and no cut-off values exist. Much research on screening and assessment tools is still needed.

The focus of nutritional epidemiology in famine situations on the under five age group, draws attention away from adults. As a result, the extent of adult malnutrition may notbe so apparent to planners. This is particularly so in areas such as southern Sudan, where famine oedema is uncommon and severemalnutrition in older people, there- fore, less easily recognised. The exclusive focus of nutritional surveys on the under five age group (in Sudan less than $115 \mathrm{~cm}$ ) also means that there is usually no baseline indicator against which adult nutritional programmes can be monitored and the impact of these programmes assessed. This makes it difficult to judge effectiveness or decide when to close programmes. We feel that older age groups should be included in nutrition surveys, especially in locations where famine has been present for a longer period of time.

\section{Inexperience}

Inexperience, at both individual and agency level, is another important reason behind the disregard for malnourished adults. In the absence of clear epidemiological data and agency guidelines, the experience of field workers and co-ordinating agencies is all the more important. Generally however, NGO and UN field co-ordinators, managers (as well as funders), are less familiar with implementing adult feeding programmes. Not only may the problem remain unrecognised, butalso expectations and the specific difficulties involved in them may be poorly understood.

\section{Complexity of Adult Feeding Programme Design}

The design of adult feeding programmes is often more complicated than that of child programmes. The potential for adult centres to become quasihospices, to contribute significantly to population displacement, or to undermine survival strategies and contribute to adverse outcomes for children of the malnourished are factors that need to be taken into account at the design stage. Frequently, other illness, particularly chronic infectious diseases such as tuberculosis (TB), and HIV will complicate a high proportion of cases. On admission it is extremely difficult to differentiate between malnutrition secondary to these illnesses and primary malnutrition, itself often complicated by other illnesses. These two forms of malnutrition, however, require differ- ent approaches to treatment. The absence of tools to quickly identify $T B$, the difficulties posed in the treatment of $\mathrm{TB}$ in unstable settings and the ethical problems involved in the spotdiagnosis of HIV, thereforecomplicateprogramme design and implementation.

Even in cases where rehabilitation is relatively straightforward, primary malnutrition responds slower to treatment than in children, with a mean length of stay of around 30 days and a mean increase in weight of less than 10 $\mathrm{g} / \mathrm{kg} /$ day ${ }^{8}$ Furthermore, in some countries socio-economic factors, such as the pressure on beneficiaries to leave centres to plant crops, or problems of compliance with a milk-based diet and inpatient care, result in higher default rates in adult centres than in those providing care for children. Addressing food preferences through supplementation of diet with local foods in the recovery phase may improve compliance. Appropriate care must be taken at all times to maintain adult dignity especially in the TFC setting.

Thesedifferences mean that adultnutrition programmes often require more involved planning and more intensive medical interventions than under five programmes. Even with this, programme results, as defined by successful exits, may be less positive than for childhood programmes. It will be necessary to evaluate adult nutrition programmes using different reference standards, since successful recovery rates of more than $75 \%$ or mortality rates of less than $10 \%$ are probably unrealistic. $^{9}$

\section{Media and Public Relations}

Nutrition programmes for adolescents and adults may not meet media expectations. Amongst the media and the increasingly influential 'agency public relations officers', images of starving infants are deemed to be more powerful in eliciting western sympathies than images of starving adults. The journalist who visited a Concern adult TFC in Sudan and requested 'to see the starving babies' was not an isolated simpleton, but represented a mainstream 
conception of what the media considers 'sexy'.

\section{Certainties and Failure of Response}

Amidst all this confusion, inadequate information and inexperience, there are some certainties. Firstly, in a severe famine, particularly towards the end of its evolution at a time when humanitarian interventions are up and running, severe malnutrition amongst the adolescent and adult population is frequently a major public health problem. Secondly, with the correct treatment, such as 24-hour therapeutic care with the careful titration of calories given to the weight and stage of recovery, rehabilitation is often successful. Even the most emaciated adults can survive and thrive. Thirdly, it is vitally important to save the lives of adults and older children as these age groups are the most economically productive and, in agrarian or agricultural communities, the major food producers. ${ }^{10}$ The deaths of mothers and older children have dramatic ramifications for survival of other children and the structure of society. Furthermore, the elderly and elders in many communities, particularly where traditions and culture are transmitted orally, are critically important to community and cultural integrity and coherence. Wefeel that in southern Sudan, particularly in Bahr el Gazal, the omission of supplementary and therapeutic feeding specifically targeting adults and adolescents was a major failing of the humanitarian response. It is time that attention to these age groups in planning and programme design was built into famine relief responses in a systematic and structured manner. The need for targeted adult and adolescent feeding programmes should always be investigated as part of any famine relief response and when necessary specialised services should be established. In addition, the many areas of uncertainty outlined above will only be clarified if such programmes are accompanied by operational research to assess the effectiveness of the different indicators and treatment regimens used. For this to progress efficiently, good inter-agency co-ordination is required to ensure the utilisation of existing knowledge in this field, standardise protocols and develop a common research agenda.

\section{References}

1. OLS Southern sector update $21 / 8 / 98$, Emergency Nutrition Programme Bahrel Ghazal, Southern Sudan.

2. In Ajiep, the epicentre of the famine in southern Sudan surprisingly the death rates of the adult and under five population registered in August were quite similar. In fact, of the 513 deaths registered immediately prior to $28 / 8 / 98,231$ were less than 20 years of age and 282 were more than 20 years of age. Furthermore in some areas where cattle camps still exist, anecdotal evidencesuggests that the under five population may be less vulnerable than older children (who may not have access to cow's milk and milk products).

3. Collins, S. 1993. The need for adult therapeutic care in emergency feeding programmes JAMA 270 *5: 637-638.

4. Concern. 1993b. Data from Concern's Adult Feeding Centre, Melanje, Angola.

5. Davies, A.P. Targeting the Vulnerable in Emergency Situations: Who is Vulnerable? Lancet, 348 (9031): 868-71 Sept 1996.

6. Mason, J.B. et al. (1996) Undernutrition. In: Murray CJL, Lopez AD, eds. Malnutrition and the burden of disease; the global epidemiology of protein energy malnutrition, anaemias and vitamin deficiencies. Cambridge, Harvard University Press.

7. In some situations it may be appropriate to combine adult and child TFCs or at least situate them on adjacent sites. If this is done, the integration of adults into the programme should be planned from the outset.

8. Collins, S. The limit of Human Adaptation to Starvation. Nat. Med. 1995; 1:810-4.

9. See Sphere Minimum Standards in Nutritional Interventions.

10. Murray, C.J.L. and A. D. Lopez. eds. The Global Burden of Disease, 1996, Harvard School of Public Health, Harvard University Press for the World Bank and World Health Organization. $\square$

The authors would like to thank Annalies Borrel.

\section{Refuge}

\section{Canada's Periodical on Refugees}

\section{Available from:}

Centre for Refugee Studies

Fax: (416) 736-5837

Email: refuge@yorku.ca

http://www.yorku.ca/research/crs 